postoperatively. The patient was symptom-free at the 5-year follow-up with unchanged $\mathrm{FEV}_{1}$.

\section{DISCUSSION}

This case illustrates that the interpretation of respiratory functional evaluation must not be considered independently of the patient context. At first, surgery was declined by overlooking the role of a neurologic deficit as the cause of the inability to perform expiratory maneuvers. We could not find other examples of lobectomy performed in quadriplegic patients with such a low preoperative $\mathrm{FEV}_{1}$. No functional data were available in the 3 lobectomies (performed by standard thoracotomy) reported by Rocco and colleagues, ${ }^{1}$ but the authors reported that preoperative evaluation may be limited, and the major emphasis must be on clinical expertise and arterial blood gas analysis to approximately determine the surgical risk. In the absence of diffuse pulmonary disease that explains major respiratory insufficiency, low preoperative $\mathrm{FEV}_{1}$ may not necessarily constitute a contraindication to surgery. In addition, vital capacity, which has been proposed as a single global measure of overall ventilatory function status in these cases, ${ }^{4}$ was not helpful. To avoid postoperative pulmonary infectious complications related to low expiratory flow rates and incapacity to expectorate, temporary tracheostomy might be a good adjunct to the surgical treatment. In a randomized controlled trial ${ }^{5}$ including 102 high-risk patients undergoing lung resection, a significantly lower rate of sputum retention was observed in the group with prophylactic tracheostomy compared with the control group, without early mortality linked to infectious lung complication.

\section{CONCLUSIONS}

The validity of pulmonary function tests in severe neurologic impairment should be considered with caution. These test results must not singly influence the decision-making for the anticipated operation when other criteria seem normal (rest of parenchyma, oxygen saturation). Prevention of complementary procedures, such as tracheostomy, might help to obtain better postoperative results.

\section{References}

1. Rocco G, Della Pona C, Massera F, Robustellini M, Rossi G, Rizz A, et al. Lobectomy for destroyed lung in quadriplegic patients. Ann Thorac Surg. 2000;69: 1002-5.

2. Jackson $\mathrm{AB}$, Groomes $\mathrm{TE}$. Incidence of respiratory complications following spinal cord injury. Arch Phys Med Rehabil. 1994;75:270-5.

3. Okubo K, Kobayashi M, Morikawa H, Hayatsu E, Ueno Y. Favorable acute and long-term outcomes after the resection of pulmonary aspergillomas. J Thorac Cardiovasc Surg. 2007;55:108-11.

4. Roth EJ, Nussbaum SB, Berkowitz M, Primack S, Oken J, Powly S, et al. Pulmonary function testing in spinal cord injury: correlation with vital capacity. Paraplegia. 1995;33:454-7.

5. Bonde P, Papachristos I, McCraith A, Kelly B, Wilson C, McGuigan JA, et al Sputum retention after lung operation: prospective randomized trial shows superiority of prophylactic minitracheostomy in hight-risk patients. Ann Thorac Surg. 2002;74:196-202.

\title{
Four-flap compound repair of thoracic hernia after sternum osteomyelitis and omentum flap
}

\author{
Christian Dirk Taeger, MD, Ulrich Kneser, MD, and Raymund E. Horch, MD, Erlangen, Germany
}

Sternal wound infections represent potentially lifethreatening complications in patients undergoing cardiovascular surgery. Although the incidence ranges from only $0.3 \%$ to $5 \%$, the condition is associated with

\footnotetext{
From the Department of Plastic and Hand Surgery, University Hospital Erlangen, Erlangen, Bavaria, Germany.

Director: Univ. Prof. Dr. med. Raymund E. Horch.

Disclosures: Authors have nothing to disclose with regard to commercial support.

Received for publication April 15, 2012; revisions received May 14, 2012; accepted for publication Aug 1, 2012; available ahead of print Aug 31, 2012.

Address for reprints: Christian Dirk Taeger, MD, Department of Plastic and Hand Surgery, University Hospital Erlangen, Krankenhausstrasse 12, Erlangen, Bavaria 91054, Germany (E-mail: christian.taeger@uk-erlangen.de)

J Thorac Cardiovasc Surg 2012;144:e117-9

$0022-5223 / \$ 36.00$

Copyright (C) 2012 by The American Association for Thoracic Surgery

http://dx.doi.org/10.1016/j.jtcvs.2012.08.004
}

significant mortality of $14 \%$ to $47 \%$ in the published data. $^{1}$

Different approaches have been tried to manage poststernotomy osteomyelitis, including surgical revision followed by open dressings or closed irrigation and reconstruction with vascularized soft tissue flaps. The omentum flap represents an alternative technique that was primarily used in the past. ${ }^{2}$ Its use was hampered by the additional surgical trauma, turning a "1-cavity" into a "2-cavity" surgery, with a much wider range of possible complications, such as pain, reduced thoracic compliance, and a significant risk of hiatal and midline hernia formation. 1

The standard techniques of sternal wound coverage such as the pectoralis major flap have limited applicability in defects in the lower third of the sternum, and a cranially 

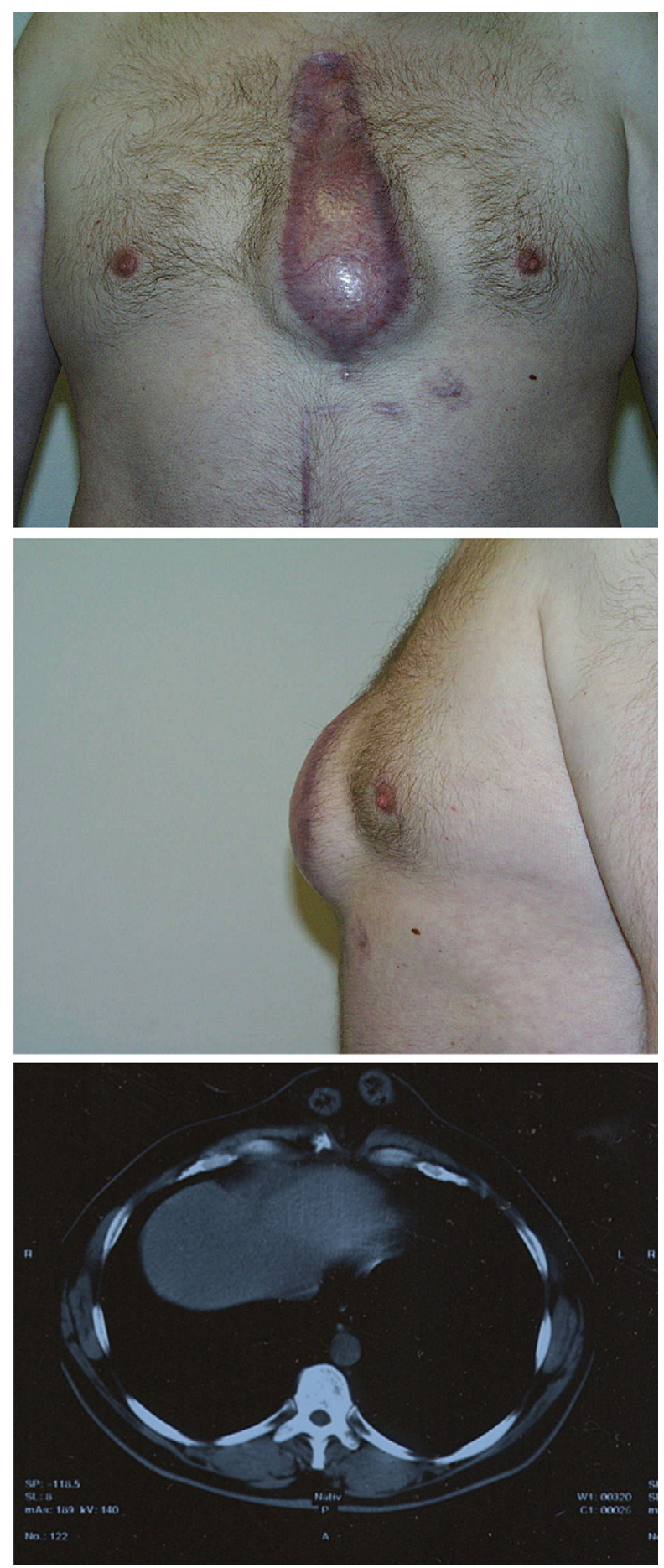

FIGURE 1. Preoperative situation.

pedicled myocutaneous flap design using the rectus muscle cannot be performed safely if ipsilateral coronary bypass surgery has been previously performed. Mobilization and transfer of the pectoralis major muscle, together with the rectus muscle, in a single unit from each side into the defect has been previously described as an alternative approach for the treatment of sternum osteomyelitis. ${ }^{3}$

Because the repair of midline and hiatal hernia after omental harvest-particularly in a formerly infected site-can be challenging, we developed a simple and reliable biologic approach that makes use of the anatomic situation in this type of hernia. Our approach represents a modification of the technique introduced by Ramirez and colleagues ${ }^{4}$ for the treatment of large lumbosacral meningomyelocele defects. In contrast to the bilateral pectoralis flap, this type of flap design facilitates sufficient hernia repair, even in the lower third of the sternum.

\section{CASE REPORT}

A 43-year-old male patient developed sternum osteomyelitis after cardiovascular surgery (Figure 1). This was initially successfully treated with an omentum flap. However, a prethoracic colonic hernia and upside-down stomach developed over time. Hence, the patient underwent hernia repair. After the colon was mobilized and repositioned into the peritoneal cavity, the peritoneum was sealed and stabilized using a polypropylene mesh. The overlying defect was reconstructed using a compound flap modified from the technique of Ramirez and colleagues. ${ }^{4}$ In so doing, the interconnected myocutaneous units of the pectoralis major and rectus abdominis muscles were advanced en bloc without any relaxing incisions or back cuts. The muscles were then compounded over the former gap, and skin closure could be performed without tension (Figure 2). The postoperative course was uneventful, and no relapse of the hernia or sternum osteomyelitis was observed.

\section{DISCUSSION}

Although sufficient treatment of sternum osteomyelitis can be achieved with an omentum flap, it can be associated with significant morbidity. The current treatment of sternum osteomyelitis involves several steps that commonly include minute and sometimes repetitive surgical debridement of all affected tissues combined with negative pressure wound therapy. When a clean wound situation has been achieved, the current state of the art treatment involves transposition of muscle tissue such as pectoralis major or rectus abdominis muscle. Nevertheless, many surgeons still use omentum flaps to treat sternum osteomyelitis. In the present case, the omentum flap was successfully used to treat the sternum osteomyelitis. However, the subsequent clinical course was complicated by herniation of the colon ventral to the thoracic wall associated with an upside-down stomach. The compound 4-flap repair provides a valuable resource to correct a thoracic wall hernia after omentum flap transposition. 

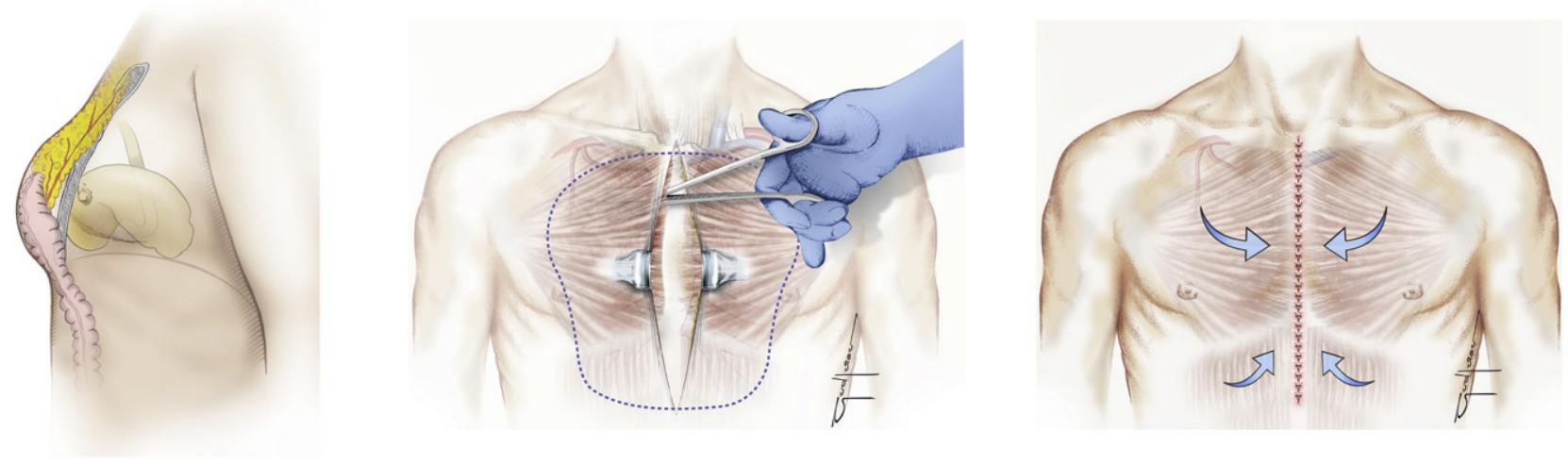

FIGURE 2. Surgical approach.

\section{References}

1. Losanoff JE, Richman BW, Jones JW. Disruption and infection of median sternotomy: a comprehensive review. Eur J Cardiothorac Surg. 2002;21:831-9.

2. Wettstein R, Erni D, Berdat P, Rothenfluh D, Banic A. Radical sternectomy and primary musculocutaneous flap reconstruction to control sternal osteitis. J Thorac Cardiovasc Surg. 2002;123:1185-90.
3. Roh TS, Lee WJ, Lew DH, Tark KC. Pectoralis major-rectus abdominis bipedicled muscle flap in the treatment of poststernotomy mediastinitis. J Thorac Cardiovasc Surg. 2008;136:618-22.

4. Ramirez OM, Ramasastry SS, Granick MS, Pang D, Futrell JW. A new surgical approach to closure of large lumbosacral meningomyelocele defects. Plast Reconstr Surg. 1987;80:799-809.

\section{Coronary artery thromboembolism as a result of left ventricular sump aneurysm after congenital heart surgery}

Timothy B. Cotts, MD, ${ }^{\mathrm{a}, \mathrm{b}}$ Felix J. Rogers, DO, ${ }^{\mathrm{d}}$ Gisela C. Mueller, MD, ${ }^{\mathrm{c}}$ and Sharlene M. Day, MD, ${ }^{\mathrm{b}}$ Ann Arbor and Trenton, Mich

Placement of a sump drain to vent the left ventricle during cardiac surgery often leaves a small apical aneurysm, which is generally considered to be a harmless remnant. We report the first case of a thromboembolic complication from

From the Departments of Pediatrics, ${ }^{\mathrm{a}}$ Internal Medicine, ${ }^{\mathrm{b}}$ and Radiology, ${ }^{\mathrm{c}}$ University of Michigan Hospitals, Ann Arbor, Mich; and Department of Internal Medicine, ${ }^{\mathrm{d}}$ Oakwood Southshore Medical Center, Trenton, Mich.

Disclosures: Authors have nothing to disclose with regard to commercial support. Received for publication July 5, 2012; accepted for publication Aug 14, 2012; available ahead of print Sept 10, 2012.

Address for reprints: Sharlene M. Day, MD, 1150 W Medical Center Dr, 7301 MSRB III, Ann Arbor, MI 48109 (E-mail: sday@umich.edu)

J Thorac Cardiovasc Surg 2012;144:e119-21

$0022-5223 / \$ 36.00$

Copyright (C) 2012 by The American Association for Thoracic Surgery

http://dx.doi.org/10.1016/j.jtcvs.2012.08.035

a sump aneurysm in an adult man 41 years after ventricular septal defect repair.

\section{CLINICAL SUMMARY}

A 46-year-old man with a history of a ventricular septal defect repair in 1968 presented with intermittent chest discomfort of approximately 4 weeks duration. The episodes were infrequent and nonexertional but were characterized by gripping tightness in the upper anterior chest. One month earlier, he had a sudden witnessed event in which he lost feeling on his right side and collapsed with loss of control of his right arm and leg. The episode lasted for 1 minute with spontaneous resolution, and the patient did not seek medical attention. He was not taking any medications at the time of presentation. Family history was notable for sudden cardiac death in a brother at age 39 years, whose autopsy showed coronary artery disease as the cause of death. His mother died of a myocardial infarction at age 62 years, and his father had coronary bypass surgery at age 60 and is alive at 74 years of age. 